\title{
Autoignition characteristics of ethers blended \\ with low cetane distillates
}

\author{
André Nicolle ${ }^{1, *}$, Nimal Naser $^{2}$, Tamour Javed ${ }^{3}$, Nicolas Rankovic ${ }^{1}$, S. Mani Sarathy ${ }^{2}$
}

1 Aramco Fuel Research Center, Aramco Overseas, Rueil-Malmaison, France

2 King Abdullah University of Science and Technology (KAUST), Clean Combustion Research Center (CCRC), Thuwal, Saudi Arabia

3 Saudi Aramco Research and Development Center, Fuel Technology Research and Development Division, Dhahran, Saudi Arabia

*Corresponding Author. Contact : andre.nicolle@aramcooverseas.com

\begin{abstract}
The introduction of high cetane components has enabled the use of low cetane base gasoline in compression ignition engines. This study provides an understanding of the autoignition characteristics of various ethers blended with light distillates. The spontaneous ignition of mixtures was herein studied both experimentally (Ignition Quality Tester) and computationally, allowing to unravel the impacts of distillate composition, ether structure and reaction progress on key ignition pathways. Various multicomponent base fuel surrogates were formulated to closely match actual fuel composition thereby accurately simulating the interplay between distillates and oxygenates. Despite its lower cetane number, di-n-butyl ether (DNBE) was found to promote a more vigorous ignition than diethylether (DEE). However, $\mathrm{OH}$ radical scavenging by p-xylene counteracts DNBE effect. Two preignition phases may be distinguished, namely oxidation initiation by ether and subsequent chemical runaway involving simultaneously fuel and ether. According to the present kinetic mechanism, direct cross-reactions between ether radicals and light distillate components have little impact on the ignition delay time under the IQT operating conditions. As ignition progress increases, ether contribution to $\mathrm{OH}$ production decreases and oxidation paths related to aliphatic and cyclic alkanes become dominant. In the case of polyoxymethylene methyl ethers, the extra production of formaldehyde during the ignition phase does not impair the overall reactivity. The respective effects of $\mathrm{OME}_{1}$ and $\mathrm{OME}_{3}$ on ignition may be explained by the emergence of a new $\mathrm{OH}$ production path from $\mathrm{OME}_{3}$ oxidation products, while methyl formate production from $\mathrm{OME}_{1}$ acts as an $\mathrm{OH}$ radical sink. Even though locally lean zones of the IQT reactor may favor specifically neopentane oxidation at the expense of $n$-hexane, the new $\mathrm{OH}$ production path remains active over a wide range of conditions. Overall, the present detailed model qualitatively captures the non-linear impact of various ethers on autoignition over the 15-30 DCN range, which makes it attractive for optimizing low cetane fuels formulation.
\end{abstract}

Keywords: Derived Cetane number, IQT, polyoxymethylene dimethyl ethers, gasoline, naphtha, ignition. 


\section{Introduction and Background}

Gasoline fuels are widely used in spark ignition (SI) engines, but research in the past decade has also shown their potential use in compression ignition (CI) engines ${ }^{1,2}$. For gasoline compression ignition (GCI) application, it has been shown that fuels with lower octane (higher cetane) such as naphtha offer improved combustion characteristics ${ }^{2}$. The introduction of high cetane components such as dialkyl ethers, among others, has opened up the use of lower cetane gasoline fuels in compression ignition engines such as gasoline compression ignition (GCI) engines ${ }^{3,4}$. Understanding the base gasoline interaction with cetane boosters, specifically gasoline / ether interaction, has thus become vital for fuel / engine co-design.

Despite recent progress in ether combustion chemistry ${ }^{5-12}$ there is a lack of fundamental studies of the interaction of commercial gasolines and ethers. Most of the studies focused on ether addition to diesel fuel blends ${ }^{13-15}$, n-alkanes ${ }^{16-19}$, or other oxygenated fuels ${ }^{20}$. Dialkyl ethers have been put forward as a clean blendstock for compression ignition engines ${ }^{21}$ as their addition to diesel fuel was shown to reduce soot emissions ${ }^{22-25}$. However, the cetane boosting effect of these ethers on light distillates such as gasoline or naphtha remains poorly understood ${ }^{26}$.

The autoignition of dimethyl ether (DME) / n-butane blends was found to give rise to competitions between the fuel components for $\mathrm{H}$ and methyl radicals ${ }^{27}$. The increase in DME blending ratio was seen to result in $\mathrm{OH}$ radical concentration increase ${ }^{19}$, thereby shortening overall ignition delays, which was related to low $\mathrm{C}-\mathrm{H}$ bonds energies in DME ${ }^{18}$. Further, nbutane addition to DME was found to result in the slight promotion of DME low-temperature oxidation paths during the first-stage ignition. Similar to n-butane ${ }^{28}$, the extent of promotion of n-pentane ignition by DME is equivalence-ratio dependent ${ }^{29}$. Co-operative effects between the individual components in the Negative Temperature Coefficient (NTC) zone were found ${ }^{30}$, but these effects were not captured satisfactorily by kinetic modeling, supposedly because of the lack of low-temperature cross-reactions. Conversely, Green et al. ${ }^{31}$ noticed that crossreactions between propane and DME do not have a significant effect on ignition, suggesting that kinetic models may be assembled from the addition of their subsets.

Interestingly, several authors found that the addition of ethers to fuels with high aromatic content does not necessarily promote ignition ${ }^{32,33}$, as a result of complex interaction of aromatics with ethers. The interaction between toluene and DME appears to be dominated by the scavenging of DME-generated radicals by toluene, leading to resonantly-stabilized benzyl radicals. Their subsequent recombination to bi-benzyl turns out to be affected by DME through altered $\mathrm{HO}_{2}$ production ${ }^{34}$.

Recently, Fikri et al. ${ }^{35}$ analyzed the ignition of Primary Reference Fuel (PRF95) / DEE mixtures and noticed that low-temperature DEE chemistry contributes to around $30 \%$ of $\mathrm{OH}$ production for only $10 \%$ vol. DEE added, and that DEE addition leads to the shift of NTC zone boundary towards higher temperatures.

Despite several dedicated studies ${ }^{36-39}$, fundamental knowledge on the ignition of polyoxymethylene dimethyl ethers $\left(\mathrm{OME}_{\mathrm{x}}\right)$ / petroleum distillate mixtures remains very scarce. It was reported that the addition of dimethoxymethane (DMM, methylal also known as $\left.\mathrm{OME}_{1}\right)$ to n-heptane results in the decrease of ignition delay times at high temperature as a linear function of DMM content ${ }^{40}$. Wang et al. ${ }^{41}$ found that HCCI engine combustion of OME 
exhibits multiple-stage ignition with pronounced low temperature heat release. The heat release profile may result from the separate oxidation of accumulated formaldehyde ${ }^{6}$.

To our knowledge, no study on the impact of ethers addition on the ignition of olefinic / naphthenic compounds was reported in the literature. However, Bogin et al. ${ }^{42}$ showed that an IQT is a suitable tool for investigating ignition kinetic mechanisms. Relying on a detailed kinetic analysis approach, the present study aims to meet the challenge of interpreting observed synergies between various light-distillates and several ether additives. For this purpose, we base our analysis exclusively on IQT experiments to decipher the mechanisms involved in autoignition enhancement as a function of ether alkylic chain length and number of ether groups in the additive.

\section{Methodology}

\subsection{Ignition Quality Tester (IQT) experiments}

Two low-cetane gasoline fuels (obtained from a refinery in Saudia Arabia) and four cetane improvers were considered in the present study. Table 1 sums up the ether added to base fuels. DEE (di-ethyl ether), DMM (dimethoxy methane) and DNBE (di-n-butyl ether) were used as high cetane additives ( $>99 \%$ purity). In addition to these pure components, a mixture of polyoxymethylene dimethyl ethers $\left(\mathrm{OME}_{\mathrm{x}}\right)$ exhibiting a Schulz-Flory distribution in the 100$250 \mathrm{amu}$ range was considered (1\% wt $\mathrm{OME}_{2}+47 \% \mathrm{OME}_{3}+29 \% \mathrm{OME}_{4}+17 \% \mathrm{OME}_{5}+6 \%$ $\mathrm{OME}_{6}$ ). Table 2 presents the characteristics of fuels investigated. For each fuel, two surrogates were formulated to fit RON, MON, DCN and PIONA using Chemkin surrogate blend optimizer ${ }^{43}$ (surrogate \#1 and \#3) and KAUST surrogate formulation tools ${ }^{44}$ (surrogate \#2 and \#4). While surrogates \#2 and \#4 focus on a limited set of well-studied palette components, surrogates \#1 and \#3 aim at matching the actual composition of the base fuel, thereby involving less wellstudied species but with higher chemical relevance ${ }^{45}$. Comparison of the PIONA and target properties such as RON, MON DCN, density, $\mathrm{H} / \mathrm{C}$ ratio and average molecular weight of the fuels, surrogates are shown in Figs. S1 and S2 in the supporting information.

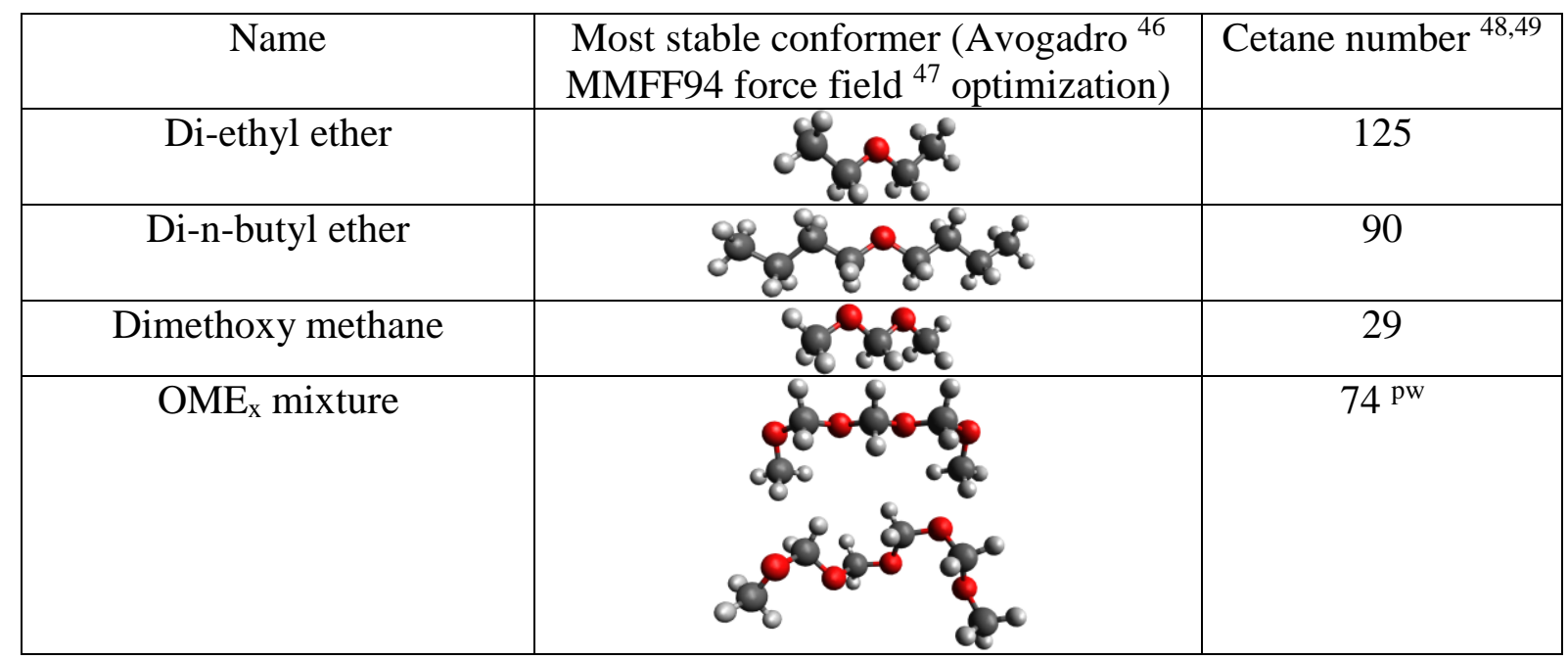

Table 1 - Cetane boosters considered in the present study. ${ }^{\mathrm{pw}}$ : present work. 


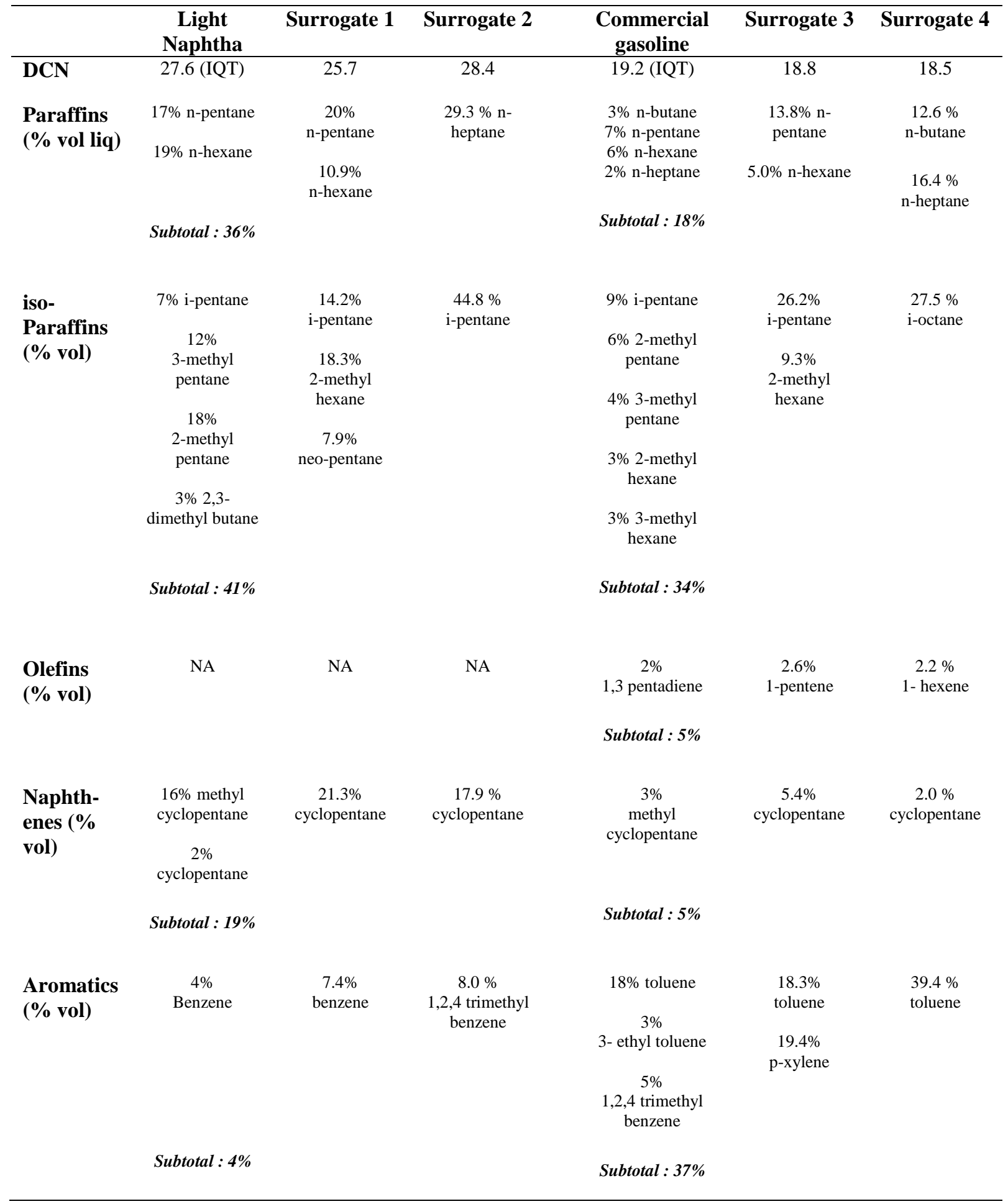

Table 2 - Specification of the fuels tested. The PIONA analysis was put together using the Detailed Hydrocarbon Analysis method outlined in ASTM D6730 and D6733. Detailed volumetric liquid composition is given for species with concentration higher than $2 \%$ volume liquid. Surrogates 1 and 2 correspond to light naphtha. Surrogates 3 and 4 correspond to commercial gasoline. DCN of surrogates are evaluated by linear-by-volume rule ${ }^{43}$. 
The ignition quality tester (IQT) was herein used to characterize CI engine fuels according to the ASTM standard D6890. The CN obtained from the IQT is referred to as the derived cetane number $(\mathrm{DCN})$ as the $\mathrm{CN}$ measurements are obtained from a constant volume combustion chamber.

The experimental setup has been already described in previous publications ${ }^{50-52}$, therefore only essential details will be provided in the following. The IQT has a chamber volume of $0.21 \mathrm{~L}$ filled with pressurized zero air that has an $\mathrm{O}_{2}$ concentration of $20.9 \mathrm{vol} \%$, remaining $\mathrm{N}_{2}$ and trace amount $(<0.1 \mathrm{ppm})$ of hydrocarbons. The prefilled zero air is at a pressure of $21.3 \mathrm{bar}$ that is heated to the required standard temperature with electric heaters. The exact chamber temperature is determined with a calibration procedure as prescribed in the ASTM D6890 standard. The fuel stored in the reservoir ${ }^{52}$ is injected into the combustion chamber with an inward opening single hole S-type nozzle, which typically has a nozzle tip temperature of 325 $\mathrm{K}$. The injected liquid fuel atomizes, evaporates and mixes with air at an overall equivalence ratio of 0.58 , close to IQT standard value ${ }^{53}$. This gradually initiates chemical reactions eventually leading to chain branching that results in a sharp rise in pressure. This sharp rise in pressure is defined as the start of ignition. The opening of the nozzle is measured with a proximity sensor, which defines the start of injection ${ }^{52}$. The time difference between the start of ignition and injection is defined as the ignition delay time (IDT) of the measured fuel at the respective condition.

The IQT is designed to measure the ignition delay time of highly reactive fuels for which the presence of low temperature heat release (LTHR) may not be apparent if it exists. However, for long ignition delay time fuels such as gasoline, LTHR may be apparent if it exists, as a result the start of ignition definition in the IQT provided system software might not provide the exact start of ignition. To account for LTHR for such fuels, the gradient method was proposed by Naser et al. ${ }^{51,52}$, which is used in the present study to measure the ignition delay times.

The IQT fuel injection system is designed for diesel fuels that have high boiling points. A series of studies ${ }^{42,54-57}$ have adopted the IQT to measure fuel ignition quality of full boiling-range gasolines and other fuels that have comparatively lower boiling points than diesel. For fuels with boiling points in the gasoline range fuel boiling issues have been reported ${ }^{42,54}$. To avoid fuel boiling issues in the present study, the pressure in the fuel line for the present experiments were maintained at 6-7 bar using $\mathrm{N}_{2}$, thereby increasing the boiling point of all the components than that defined at atmospheric conditions. This was to an extent helpful in reducing the fuel boiling issues for gasoline-like fuels. For the highly volatile fuels used in the present study, i.e., light naphtha, to minimize the exposure time of the fuel to the hot injector tip to prevent fuel boiling in the delivery lines the bleed valve ${ }^{62}$ was opened to bleed vaporized fuel just before injection. This enabled fresh fuel to fill the lines prior to injection. The higher fuel line pressure and the timely operation of the bleed valve prevents long exposure of the fuel to the injector tip, which reduces compositional variations in the injected fuel resulting from boiling issues.

Each DCN measurement involves 15 pre-injections whose data are not logged followed by 32 main injection events with the data logged. The data obtained is then processed to calculate the ignition delay time with the gradient method and the average of the 32 injections is used in the present study. As mentioned above the standard temperature is obtained by performing a calibration procedure that involves the IDT measurement of $n$-heptane. The chamber 
temperature is adjusted such that the average of three runs (i.e., 15 pre-injections and 32 main injections for each run) is $3.78 \pm 0.01 \mathrm{~ms}$. This temperature is then fixed for IDT measurement of all other fuels. The DCN is then calculated with the average IDT $\left(\tau_{\text {id }}\right)$ using Eq. (E1). The standard deviation of 32 main injection for all the measurements are also provided in the present study. For IDT in the range of $3.1-6.5 \mathrm{~ms}$ Eq. (E1a) is used, whereas for all IDT outside the range of $3.1-6.5 \mathrm{~ms}$, Eq. (E1b) is used.

$$
\begin{gathered}
D C N=4.46+\left(\frac{186.6}{\tau_{i d}}\right) \\
D C N=83.99\left(\tau_{i d}-1.512\right)^{-0.658}+3.547
\end{gathered}
$$

Excellent correlation between $\mathrm{CN}$ and DCN for IDT in the range of 3.1-6.5 ms is given by Eq. (E1a). Equation (E1b) is less precise than (E1a) but many recent publications ${ }^{57-60}$ have used this correlation for DCN evaluation.

\subsection{Chemical kinetic modeling}

The present kinetic mechanism (10601 reactions and 2444 species) was obtained by adding DEE, DNBE and $\mathrm{OME}_{\mathrm{x}}$ subsets to multicomponent KAUST-LLNL-NUIG FACE gasoline mechanism ${ }^{61}$. The DEE subset was extracted from the mechanism of Tran et al. ${ }^{63}$ which includes new primary low-temperature reaction paths leading to acetic acid and acetic anhydride and was coupled to the previously developed high-temperature model ${ }^{64}$. The DNBE subset was taken from a recent stirred reactor study performed by Thion et al. ${ }^{65}$ over an extended range of residence times and equivalence ratios. The authors refined the rates constants for ketohydroperoxide decomposition initially proposed by Cai et al. ${ }^{66}$ and calculated the rate constants of the $\beta$-scissions of DNBE radicals using TST/RRKM modeling. Both DEE and DNBE subsets are able to account for the two-NTC-zone occurrence reported for these ethers. The $\mathrm{OME}_{2-3}$ subset from Tsinghua group ${ }^{67}$ includes both low and high temperature chemistry. It was complemented with the DMM subset generated in a recent collaboration between Tsinghua, Orleans and Sandia ${ }^{68}$. Figure 1 shows a validation of the full mechanism against available experimental measurements. In the present study, the $\mathrm{OME}_{\mathrm{x}}$ mixture (DCN of 74) was represented by $\mathrm{OME}_{3}$ due to its reported cetane number of $78^{41}$. 

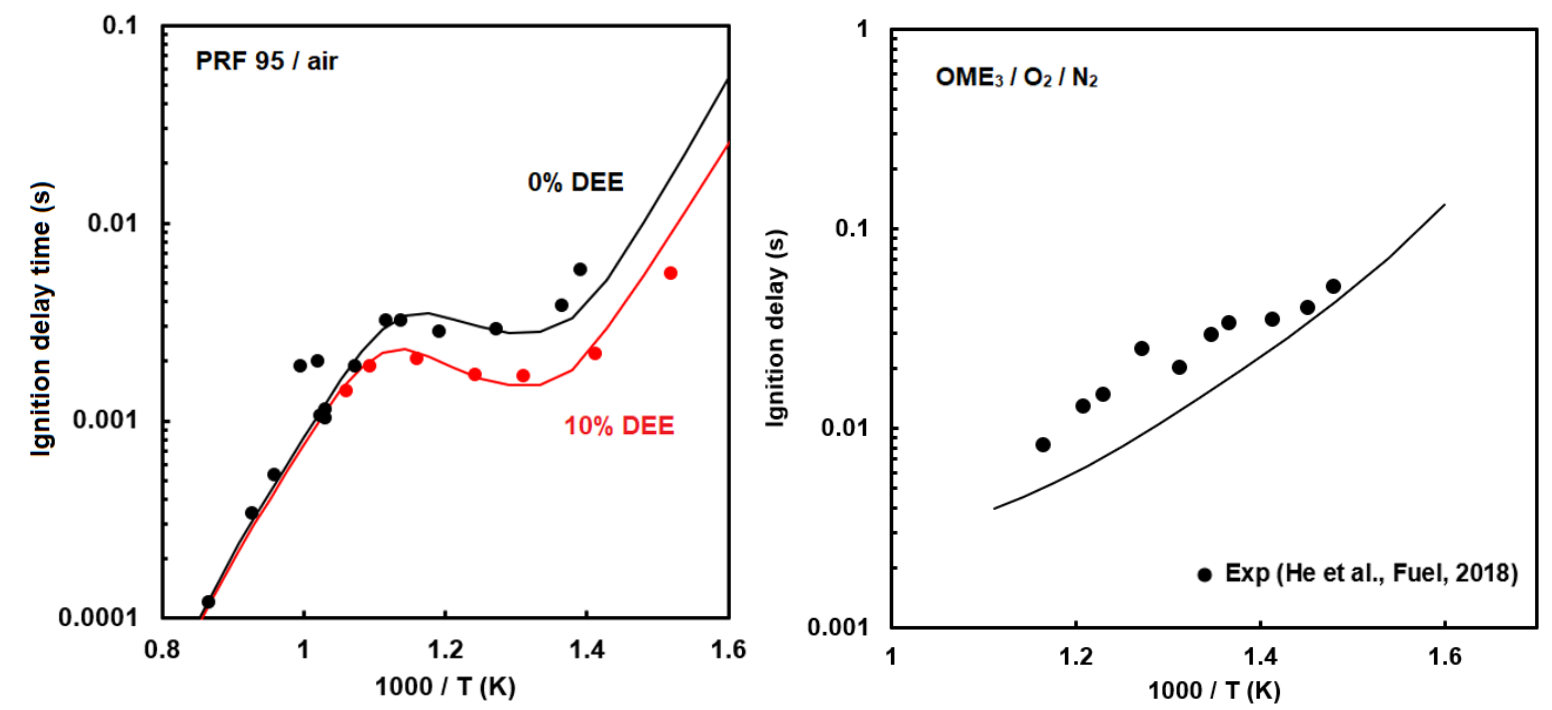

Figure 1 - Present model (lines) validation against shock tube IDT (symbols) of Fikri et al. ${ }^{35}$ and He et al. ${ }^{6}$. The modeled ignition delay corresponds to the time required to reach the maximum heat release rate (main inflection point).

\subsection{IQT modeling}

A multizone model using the Chemkin Pro software package ${ }^{69}$ was employed to model the IQT. The IQT zones are modeled as closed gas-phase homogeneous reactors which interact with each other exclusively through pressure work (physical expansion due to combustion), the total volume being held constant ${ }^{70}$. The present model does not take into account spray formation and evaporation. However, recent calculations carried out at KAUST ${ }^{71}$ demonstrate that for volatile low-reactivity fuels such as iso-octane, the evaporation time of these species under IQT conditions is significantly shorter than chemical ignition time. Complementary calculations presented in the supporting information indicate that the physical delay time associated to the spray breakup and subsequent droplets evaporation may represent typically $23 \%$ of the overall ignition delay time for a gasoline with a DCN of 20 . The physical/ overall ignition delay ratio becomes higher that $50 \%$ for $\mathrm{DCN}>35$ due to the shortening of the gasphase chemical ignition delay. This provides an upper DCN value of 35 for the present model validity. The addition of DNBE was previously seen to impact sprays atomization ${ }^{72}$. According to the Sauter Mean Diameter (SMD) expression presented in the supporting information, the use of DNBE (resp. DEE) instead of gasoline is expected to result in an increase (resp. a decrease) of the SMD by $20 \%$ for DNBE (resp. 12\% for DEE) due to the higher (resp. lower) viscosities ${ }^{73}$ and surface tensions ${ }^{74}$ of these ethers than those of gasoline. As moderate amounts $(<25 \%)$ of ethers are herein blended to the base fuel, our calculations indicate that the atomization-related effect of ethers on DCN should remain limited $(<1)$.

The computed IDT was defined as the time required for the all zones of the system to reach $\mathrm{T}_{\text {init }}$ $+400 \mathrm{~K}$, which coincides well with the occurrence of the average temperature inflection point (relative deviation $<5 \%$ ). The DCN is then deduced from computed IDT using the same correlation as the one used experimentally (E1). The zone volume fractions of the 20-zone model obtained by Osecky et al. ${ }^{75}$ at $20 \mathrm{~ms}$ contact time were normalized to the present overall equivalence ratio (0.58). The same temperature distribution accounting for the evaporating 
cooling of iso-octane was used for all fuels blends. Osecky et al. showed that this distribution is relevant to reproduce ignition delays and that relying on a late macromixing state (i.e. $20 \mathrm{~ms}$ instead of typically 7-15 ms for the fuels investigated) would not significantly affect the predicted ignition delay times. Additional calculations presented in Figure 2 demonstrate that the present multizone model is indeed able to predict the measured DCN of a variety of Toluene Primary Reference Fuels (TPRFs) within a reasonable error range ( $\mathrm{DCN} \pm 4$ ) over the range 20-35, taking implicitly the physical delay into account through Osecky's initial gas-phase mixing state. In all calculations, the pressure was 21 bar. The adopted 20-zone reactor parameters are provided in table S3 (supporting information). In the kinetic analysis, normalized rate-of-production (ROP) of a given reaction was obtained by dividing its species production rate by the sum of the rate-of-progress variables over all reactions producing the targeted species ${ }^{76}$.

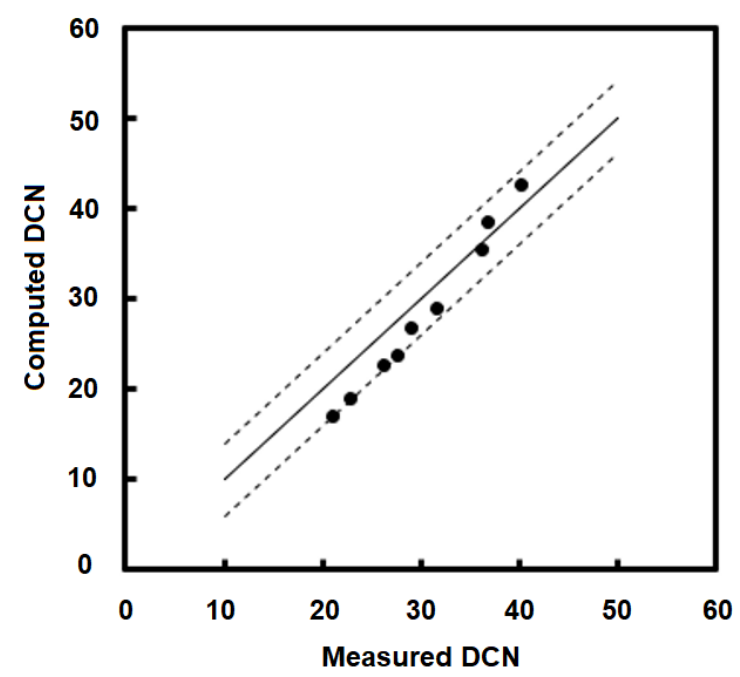

Figure 2 - Parity plot for a wide range of TPRFs ${ }^{52}$. The DCN was computed using Osecky's 20-zone model and equation (E1). The dotted lines correspond to $y=x \pm 4$.

\section{Results and Discussion}

\subsection{Phenomenological description of cetane enhancement}

For the two investigated base fuels, the promoting effects of ethers were found to follow the order DNBE > DEE > OME (Figure 3). Hence, the intuitive order DNBE < DEE that would come out of linear blending rules is actually reversed. This might be due to a synergetic chemical behavior at low ether concentrations or to higher DEE volatility which influences temperature and concentration stratification ${ }^{77}$.

Prior to proceeding to detailed kinetic modeling, the impact of additives on IDT (and hence DCN) may be first rationalized by the a simple ignition time scale analysis ${ }^{78}$ accounting for the sequencing of fuel/additive interaction with ignition progress. 


$$
\tau_{\text {id }}=\tau_{\text {initiation }}+\tau_{\text {runaway }}
$$

During initiation phase, it can be assumed that ether and fuel oxidation are occuring almost sequentially, as will be demonstrated by the chemical kinetic analysis below (section 3.3). Therefore, the corresponding delay may be estimated as a volume-weighted sum of individual reaction times (derived from table 1 properties and (E1)).

$$
2 \tau_{\text {initiation }}=v_{\text {additive }} \tau_{\text {additive }}+\left(1-v_{\text {additive }}\right) \tau_{\text {fuel }}
$$

After initiation, chemical branching leads to simultaneous runaways of fuel and additive. Thus, the corresponding delay involves an harmonic mean of individual reaction times.

$$
\frac{2}{\tau_{\text {runaway }}}=\frac{v_{\text {additive }}}{\tau_{\text {additive }}}+\frac{1-v_{\text {additive }}}{\tau_{\text {fuel }}}+\alpha v_{\text {additive }}\left(1-v_{\text {additive }}\right)
$$

The third term of the right-hand side of (E4) accounts for the interaction ${ }^{79}$ between fuel and additive. While this term was found to be negligible for $\mathrm{DEE}$ and $\mathrm{OME}_{\mathrm{x}}$, a value of $\alpha=0.75$ (i.e. nearly 3 times Lorentz's average of reciprocal times ${ }^{80}$ ) was required to reproduce the concavity of DNBE plot displayed in Figure 3. Note that the present volume-weighted hybrid mixing rule performs better than its molar counterpart (Figure 3 inset) at low ether content (< $10 \%$ vol.). At higher ether contents (>10\% vol.), the present phenomenological mixing rule fails to capture cetane boost accurately, calling for detailed chemical kinetic modeling.
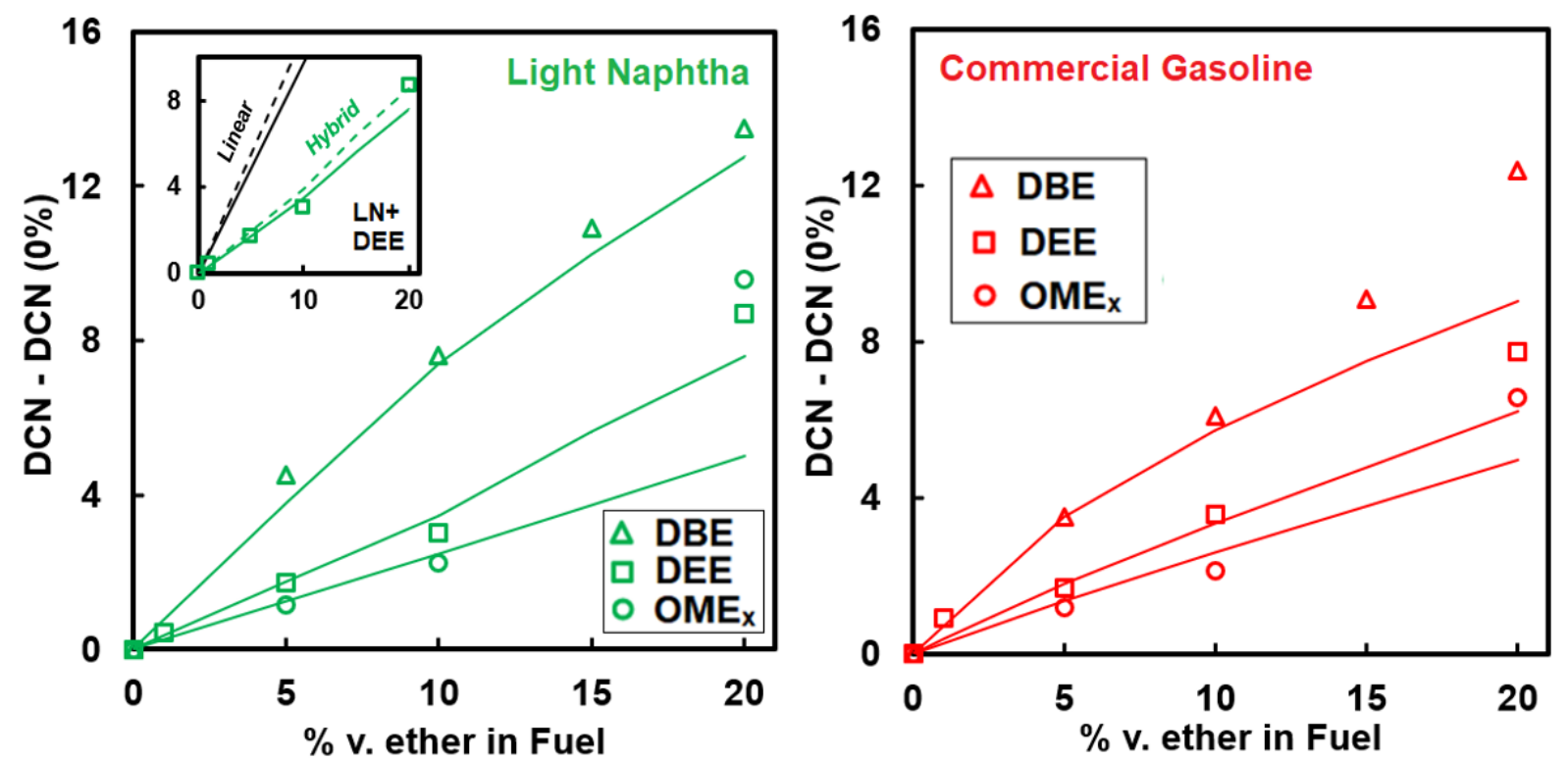

Figure 3 -Comparison of cetane boosts of different ethers for the two base fuels considered. Symbols represent experimental measurements and lines represent phenomenological mixing rule (equations (E2)-(E4) with $\alpha=0.75$ for DNBE). Inset on the top left presents a comparison of the present volume-based hybrid mixing rule (green continuous line) with the volume-based linear mixing rule (black continuous line) using base fuel DCN derived by IQT in the present work. Corresponding molar mixing rules are depicted by dashed lines. 


\subsection{Effect of the dialkyl ether chain length on ignition kinetics}

Figure 4 shows a comparison between experimental and modeled DCN in the case of dialkyl ether addition. Measured IDT and relative experimental errors are presented in the supplementary material (Figure S6). Uncertainty calculations using polynomial chaos expansion $^{81}$ (MUM-PCE) reveal that $30 \%$ represents a lower boundary of error estimate of IDT prediction associated with the present set of Arrhenius prefactors, let alone the additional uncertainty on thermochemical properties ${ }^{82}$. It is important to notice that owing to the strong non linearity of equation (E1), a relatively modest error on IDT can induce a large error on DCN.
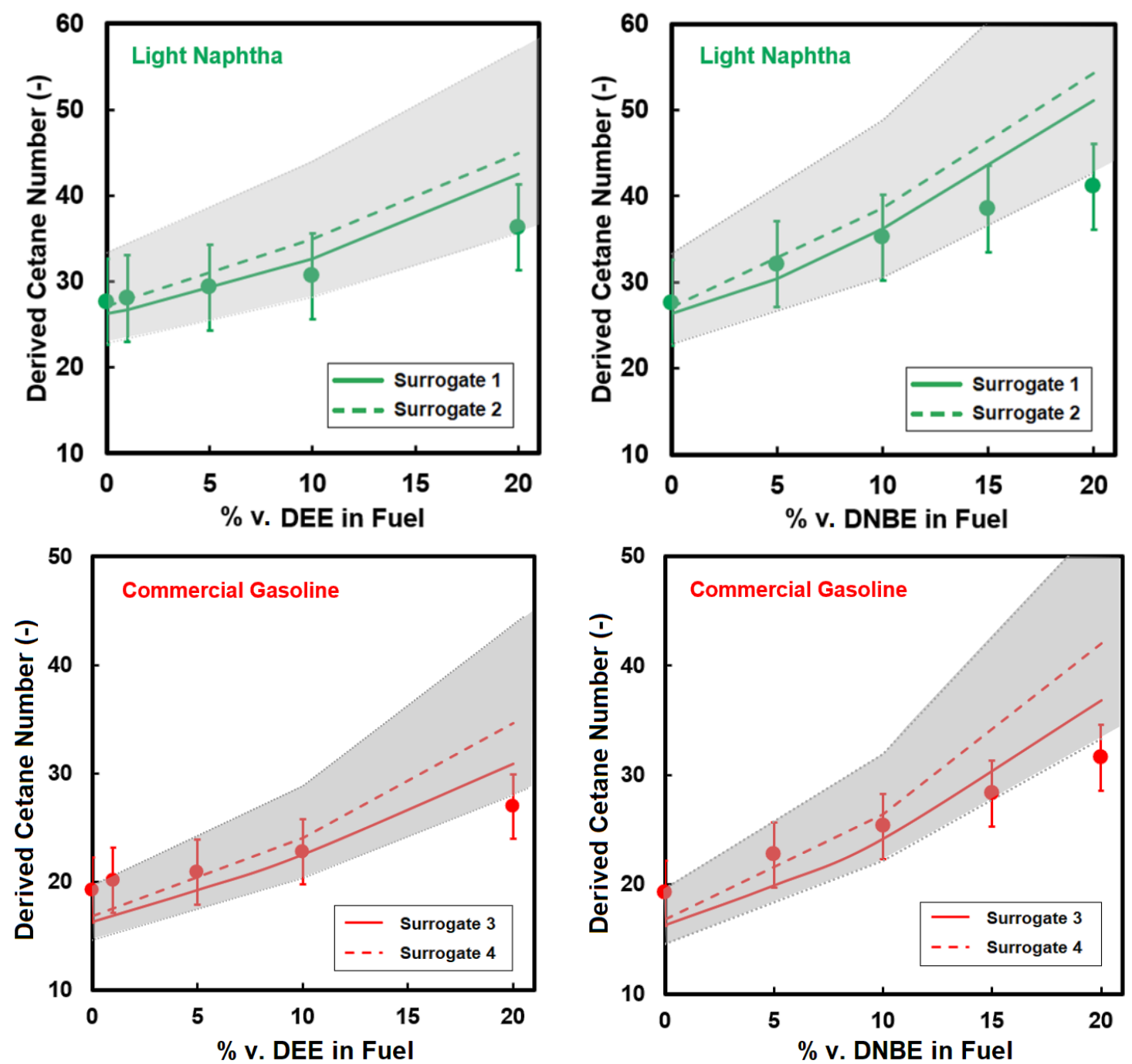

Figure 4-Measured (symbols) and predicted (lines, surrogates 1 and 2) DCN boost effect of dialkyl ethers on light naphtha (first row) and commercial gasoline (second row). Continuous and dashed lines stand respectively for surrogates 1 and 2 (top row)

and respectively for surrogates 3 and 4 (bottom row). Experimental error bars correspond to the value estimated in figure S5 (supporting information). Shaded areas are related to surrogate 2 (top row) and 4 (bottom row) and corresponds to $30 \%$ uncertainty on IDT (see text). 
For all surrogates, the modeled impact of various ethers on DCN is in reasonably good agreement with measurements for ether concentrations lower than $20 \%$ given the respective uncertainties (Figure 3). However, surrogates tend to slightly overpredict the slope of cetane boost with respect to dialkyl ether concentration. This might be partly due to specific termination reactions not included in the present kinetic scheme and to the behavior of the 20zone model as illustrated on Figure 2 by the migration of the points of the parity plot towards its upper half-plane with increasing DCN.

Under the present conditions, bringing the surrogate formulation a step closer to the actual fuel composition (i.e choosing surrogates $1 / 3$ over 2 / 4) does not appear to be beneficial for predicting the increase of global reactivity induced by ethers addition. Nevertheless, it can be expected that the use of surrogates 1 and 3 would allow a more instructive view of the coupling of dialkyl ethers and naphtha oxidations as a result of their more detailed compositions. As an illustration, a reversal of importance of relative OH ROP of straight-chain and branched-chain alkanes oxidation paths can be noticed (respectively 21 and $25 \%$ for surrogate 3 but 32 and $20 \%$ for surrogate 4 ) for commercial gasoline / 10\% DNBE mixture at $10 \% \tau_{\text {id }}$ (ignition delay). The same trend can be noted for $\mathrm{OH}$ consumption paths as well. The reason for this is that the iso-alkanes considered in surrogate 3 are much less branched than iso-octane (used in surrogate 4) and hence more reactive over the temperature range of interest.

Our rate-of-production analyses performed with surrogate 1 reveal that at $1 \% \tau_{\text {id }}$, the first $\mathrm{O}_{2}$ addition on alkyl ether radicals and the second $\mathrm{O}_{2}$ addition on $\mathrm{QOOH}$ radicals are proceeding respectively $21 \%$ and $10 \%$ faster in presence of $10 \%$ DNBE than with $10 \%$ DEE. This may be due to the higher methylene / methyl ratio in DNBE, which favors peroxidation. As a consequence, DNBE addition results in prompter ether alkyl peroxides formation (mole fractions of respectively 530 and 25 ppbv for $10 \%$ DEE and $10 \%$ DNBE at $25 \% \tau_{\text {id }}$ ) throughout the degenerate chain branching process which in turn results in the shortening of ignition delay.

As can be noticed on figure 5, the normalized sensitivity of ignition delay with respect to kinetic preexponential factors

$$
\mathrm{S}_{j}=\frac{A_{j}}{\tau_{i d}} \frac{\partial \tau_{i d}}{\partial A_{j}} \approx \frac{\tau_{i d}\left(1.1 A_{j}\right)-\tau_{i d}\left(A_{j}\right)}{0.1 \tau_{i d}\left(A_{j}\right)}
$$

This comes hand in hand with the involvement of $\mathrm{HO}_{2}$ in $\mathrm{H}$-abstraction on DEE (accounting for $16 \%$ of DEE consumption at $10 \% \tau_{\mathrm{id}}$ ), whereas $\mathrm{OH}$ is herein the only fast $\mathrm{H}$-abstractor for DNBE. At low ignition progress, DEE dissociates readily to ethylene (7\% of DEE consumption at $0.01 \tau_{\mathrm{id}}$ ), while $\mathrm{C}-\mathrm{O}$ scission in DNBE does not happen readily at low temperature ${ }^{65}$, making $\mathrm{H}$-abstraction a prerequisite of unimolecular decomposition to reactive 1-butyl radical. The different reactivities of the abovementioned $\mathrm{C}_{2}-\mathrm{C}_{4}$ decompositions products with the base fuel components give rise to very distinct synergetic effects. Also, the increase of ignition delay through decomposition of alkoxyalkyl radicals (by substracting carbon from the ether peroxidation path) appears to be less significant for DNBE than for DEE. Note that the sign of sensitivity of production of n-pentyl radical depends on its class due to differing propensities to peroxidation. Finally, adding H-Abstraction reaction by ether radicals on aliphatic alkanes and cyclopentane (with kinetic parameters evaluated by RMG $3^{83}$ and provided in supporting material) to the kinetic scheme was found to have negligible impact on ignition delay time (< $0.1 \%$ ) over the range of ether concentrations investigated. This tends to indicate that naphtha and ether are mainly interacting through the $\mathrm{C}_{0}-\mathrm{C}_{4}$ radical pool. 


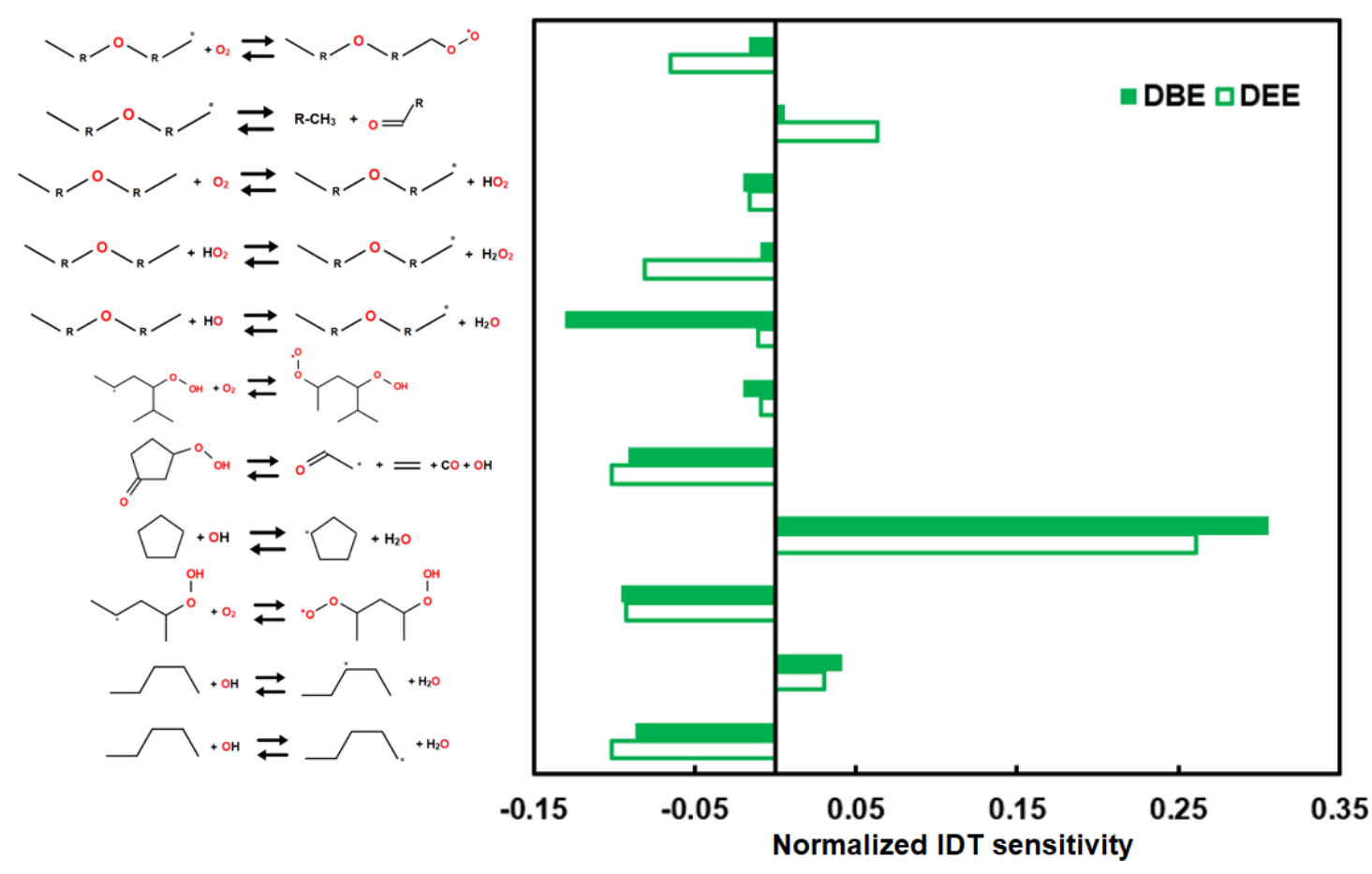

Figure 5 - Main reactions affecting IDT for light naphtha $+10 \%$ ether mixtures (Surrogate 1 was used in the calculations). Formula were generated by OpenBabel ${ }^{84}$ software.

3.3 Effect of the base fuel composition on ignition kinetics

From the experimental findings displayed in section 3.1, we may notice (Figure 3) that both base fuels give rise to similar additive rankings in term of cetane boost (i.e. DNBE $>$ DEE $\left.>O M E_{x}\right)$, although the interaction with DNBE shifts from synergetic to antisynergetic as naphtha is replaced by gasoline. In fact, an increase of 7.6 and 6.1 in DCN is respectively measured for naphtha and gasoline at $10 \%$ DNBE, whereas the linear-by-volume mixing rule provides increases of 6.2 and 7.1, respectively. This illuminates the primordial role of base fuel composition, notably the aromatic content ${ }^{34}$, in counteracting the promoting effect of ethers. Figure 6 further shows that replacing naphtha by gasoline does in fact result in the dramatic increase of the importance of the following $\mathrm{OH}$ radical scavenging reaction<smiles>Cc1cc(C)cc(OCCc2c(C)ccc(C)c2O)c1</smiles>

The emergence of this inhibitory path may be attributed to the lower cycloalkanes and higher p-xylene and toluene contents in gasoline. Despite their similar concentrations in surrogate 3 , toluene and $\mathrm{p}$-xylene exhibit differing propensities to scavenge $\mathrm{OH}$ radicals as they account respectively for $5 \%$ and $8 \%$ of $\mathrm{OH}$ consumption at $10 \% \tau_{\mathrm{id}}$ for gasoline / $10 \%$ DNBE mixtures. 


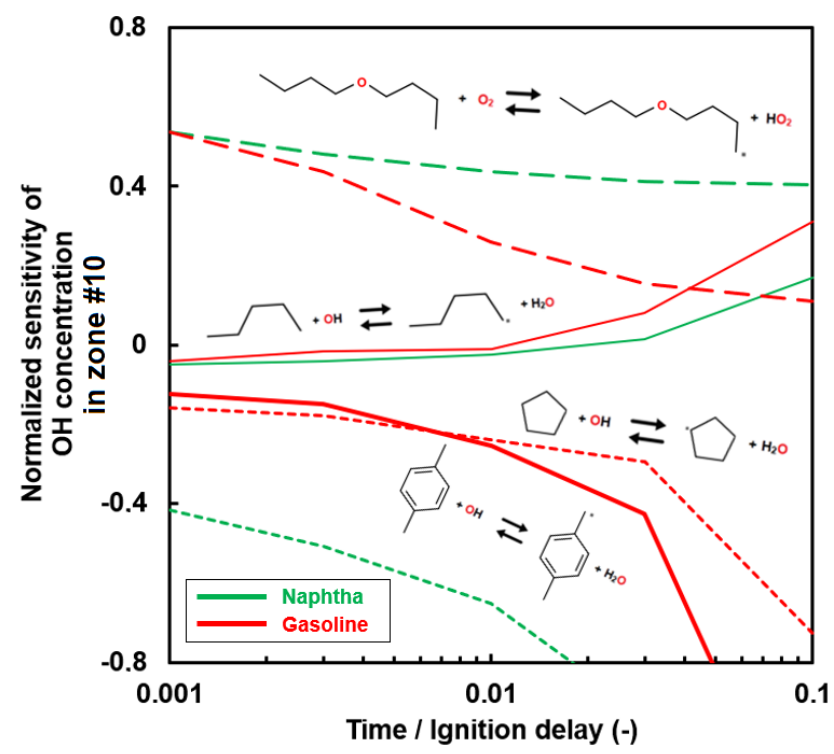

Figure 6 - Normalized sensitivities of $\mathrm{OH}$ concentration with respect to kinetic preexponential factors in zone \#10 of the IQT chamber (corresponding to volumeaveraged thermochemical conditions in IQT) for the ignition of fuel $+10 \% \mathrm{v}$. DNBE mixtures. Green and red curves stand respectively for naphtha and gasoline. Surrogates 1 and 3 were used in the calculations. Sensitivities of monoaromatics + $\mathrm{OH}$ reactions are not displayed for naphtha ignition as they are lower than 0.1.
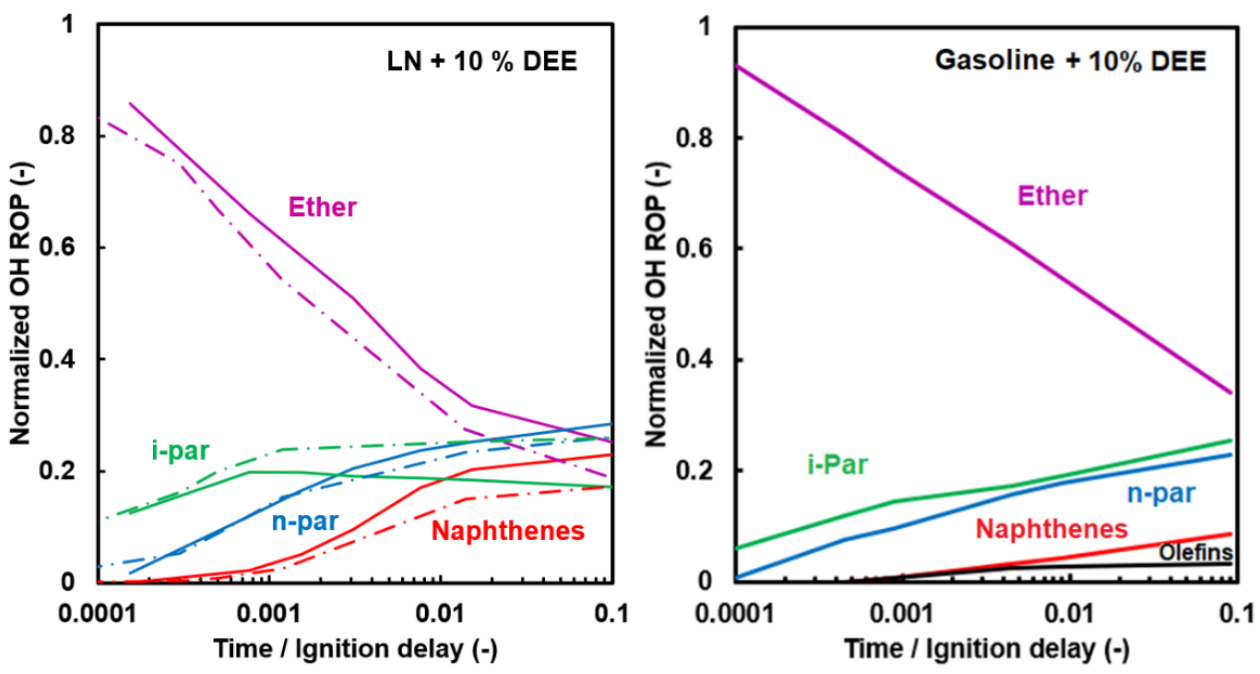

Figure 7 - Predicted contributions of chemical families to $O H$ average rate-ofproduction (ROP) inside the IQT chamber for the ignition of fuel $+10 \% \mathrm{DEE}$ mixtures (Left : Surrogate 1. Right : Surrogate 3). Dash-dotted lines denote the results obtained by a single-zone model at $756 \mathrm{~K}$ and $\phi=0.58$ (volume-averaged conditions).

The base fuel composition may not only impact $\mathrm{OH}$ consumption paths but also the relative contributions of chemical families to $\mathrm{OH}$ production during pre-ignition phase. Figure 7 illustrates the sharp decrease of ether contribution to $\mathrm{OH}$ production with ignition progress $(\mathrm{t} /$ $\tau_{\mathrm{id}}$ ), substantiating the fuel-ether interaction phenomenology previously put forward in section 3.1. Mixture stratification (continuous vs. dash-dotted lines) contributes to increase ether 
promoting effect at the expense of iso-paraffins contribution to $\mathrm{OH}$ production. Utilizing the single-zone modeling neglects the contribution of temperature and mixture/equivalence-ratio stratification, which have significant effect on ignition kinetics.

While ether contribution to $\mathrm{OH}$ dominates up to $1 \% \tau_{\text {id }}$ for light naphtha, its dominance is extended to times as high as $10 \% \tau_{\text {id }}$ for commercial gasoline, due to a lower reactivity of base fuel. This compensation effect explains why cetane boosts of $20 \%$ DEE addition in quite similar for naphtha and gasoline (respectively +9 and +8 on experimental DCN).

According to our rate-of-production analyses for fuel $+10 \%$ DEE blends, $\mathrm{OH}$ early production $\left(\mathrm{t}<1 \% \tau_{\mathrm{id}}\right)$ by ether involves mainly hydroperoxyl radical decomposition<smiles>CCOC(C)OO</smiles>

and subsequent peroxohydroperoxy radical decomposition to keto species. As time increases, aliphatic iso-alkanes are increasingly competing with ether through the production of cyclic ethers and ketohydroperoxides.

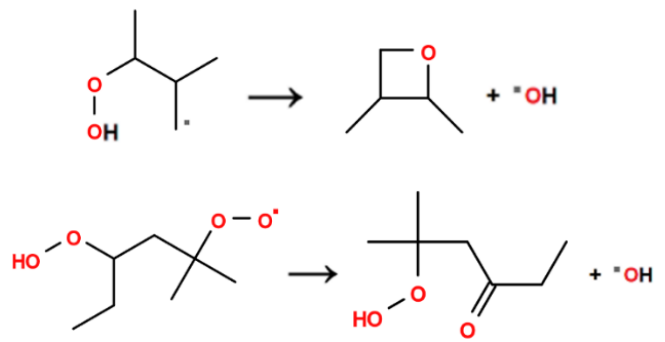

Then, for $\mathrm{t}>0.1 \% \tau_{\mathrm{id}}$, the oxidation of straight-chain alkanes takes over for $\mathrm{OH}$ production through degenerate chain branching.<smiles>COOC(C)CC(C)OO</smiles>

Interestingly, cycloalkane oxidation starts releasing significant amounts of $\mathrm{OH}$ much later than aliphatic alkanes, proceeding mainly through the following reaction (E11)

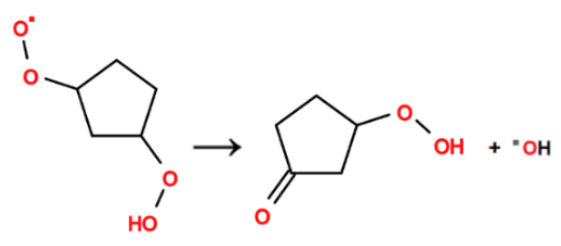

The significant contribution of cycloalkanes to reactivity in the NTC region confirms previous findings on FACE gasolines ${ }^{61}$. However, in the case of commercial gasoline, which contains six times less cycloalkanes than light naphtha, $\mathrm{OH}$ production by cyclopentane oxidation encounters competition from 1-pentene oxidation through Waddington reaction (E12).<smiles>COOC(CO)CCCCCCCCO</smiles> 
Similar pathways can be identified for fuel $+10 \% \mathrm{OME}_{\mathrm{x}}$ mixtures, with the formation of trioxane derivatives (E13).

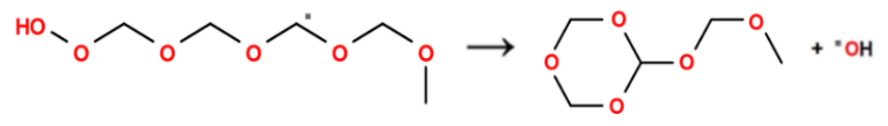

\subsection{Effect of the polyoxymethylene ether chain length on ignition kinetics}

Similar to the case of alkyl ethers, all proposed fuel surrogates were found to correctly reproduce the experimental observations. Figure 8 shows that dimethoxymethane (methylal, $\mathrm{DMM}$ or $\mathrm{OME}_{1}$ ) addition to either of the two base fuels does not result in a significant cetane boosting effect. Unlike in the case of dimethoxymethane, $\mathrm{OME}_{\mathrm{x}}$ addition exhibits a strong and non-linear effect on DCN. Hence, increasing the level of polymerization of $\mathrm{OME}_{\mathrm{x}}$ is beneficial to cetane boosting effect. Although $\mathrm{OME}_{\mathrm{x}}$ mixture is herein represented by $\mathrm{OME}_{3}$ due to the lack of validated oxidation mechanisms for $\mathrm{OME}_{4+}$, the present model is able to capture correctly this effect at low OME concentrations ( $<20 \%$ vol. liq.).
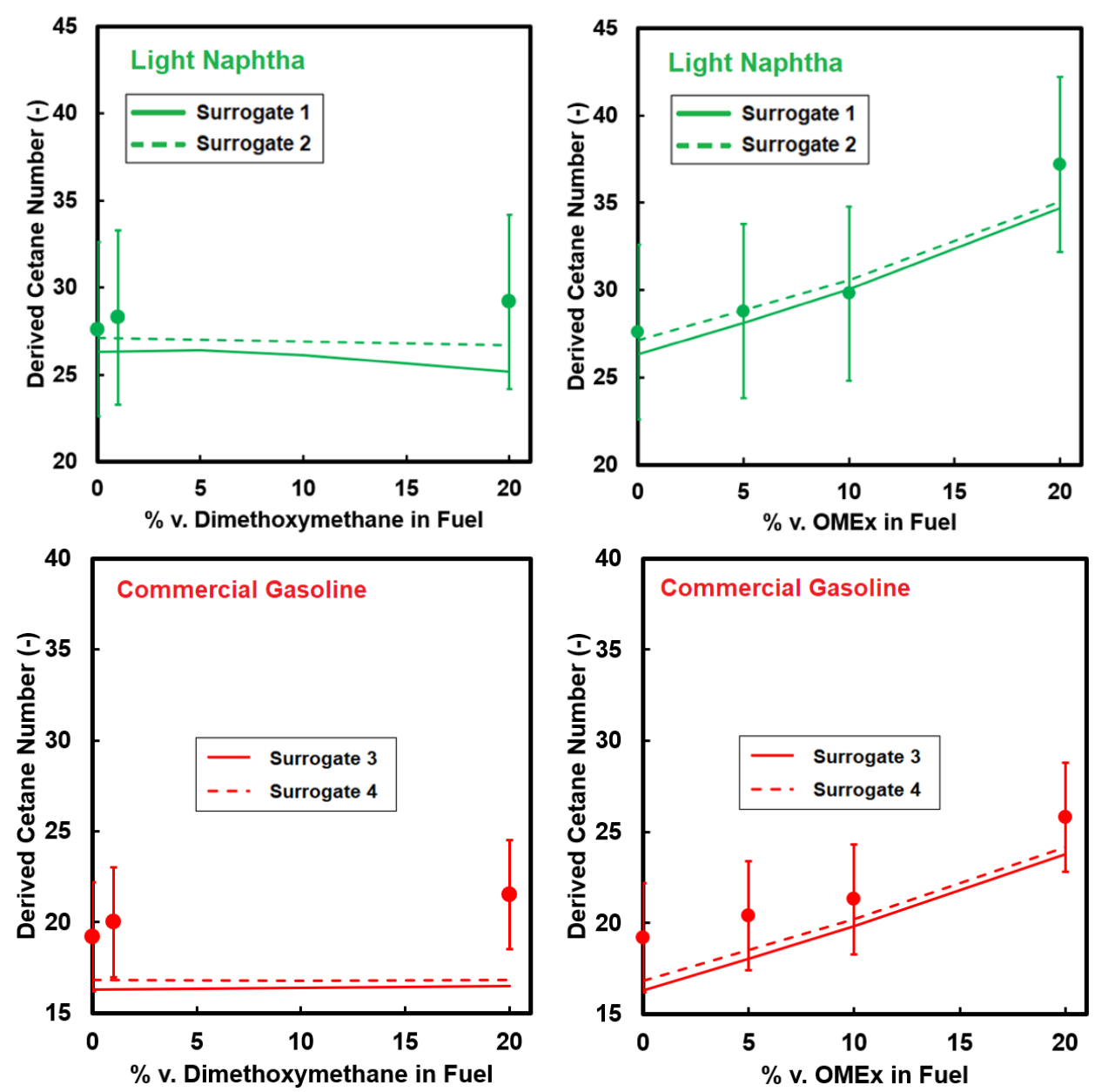

Figure 8-Measured (symbols) and predicted (lines) cetane number boost effect of polyoxymethylene dimethyl ethers. Green and red colors denote respectively light naphtha (first row) and commercial gasoline (second row). Continuous and dashed 
lines stand respectively for surrogates \#1/\#3 and\#2/\#4. Error bars correspond to the value determined in figure S6 (supporting information).

While methyl formate formed from methylal oxidation does not readily oxidize (Figure 9), according to the present model, the production of hydroperoxy-methylformate $\left(\mathrm{HO}_{2} \mathrm{CH}_{2} \mathrm{OCHO}\right)$ from $\mathrm{OME}_{3}$ contributes to accelerate chain branching. Indeed, $\mathrm{HO}_{2} \mathrm{CH}_{2} \mathrm{OCHO}$ decomposition rate through<smiles></smiles>

is found to be nearly 4 times higher for $\mathrm{OME}_{3}$ than for $\mathrm{OME}_{\mathrm{x}}$. This effect is in line with previous evidence of the key role of $\mathrm{HO}_{2} \mathrm{CH}_{2} \mathrm{OCHO}$ in cool flame DME chemistry ${ }^{85,86}$. Although methyl formate oxidation is known to be quite slow ${ }^{87}$, in presence of $\mathrm{OME}_{3} \mathrm{HO}_{2} \mathrm{CH}_{2} \mathrm{OCHO}$ production proceeds via DMM3B (SMILES COCOCO $[\mathrm{CH}] \mathrm{OC}$ ) and DMM3C (SMILES $\mathrm{COCO}[\mathrm{CH}] \mathrm{OCOC}$ ) paths, whereas DMM3A (SMILES COCOCOCO $[\mathrm{CH} 2]$ ) path leads essentially to $\mathrm{C}_{5}$ hydroperoxy-polyoxymethylene ether formation. As a result, $\mathrm{OME}_{3}$ oxidation relies on multiple $\mathrm{OH}$ production paths involving $\mathrm{C}_{2}, \mathrm{C}_{3}$ and $\mathrm{C}_{5}$ ethers peroxidation.
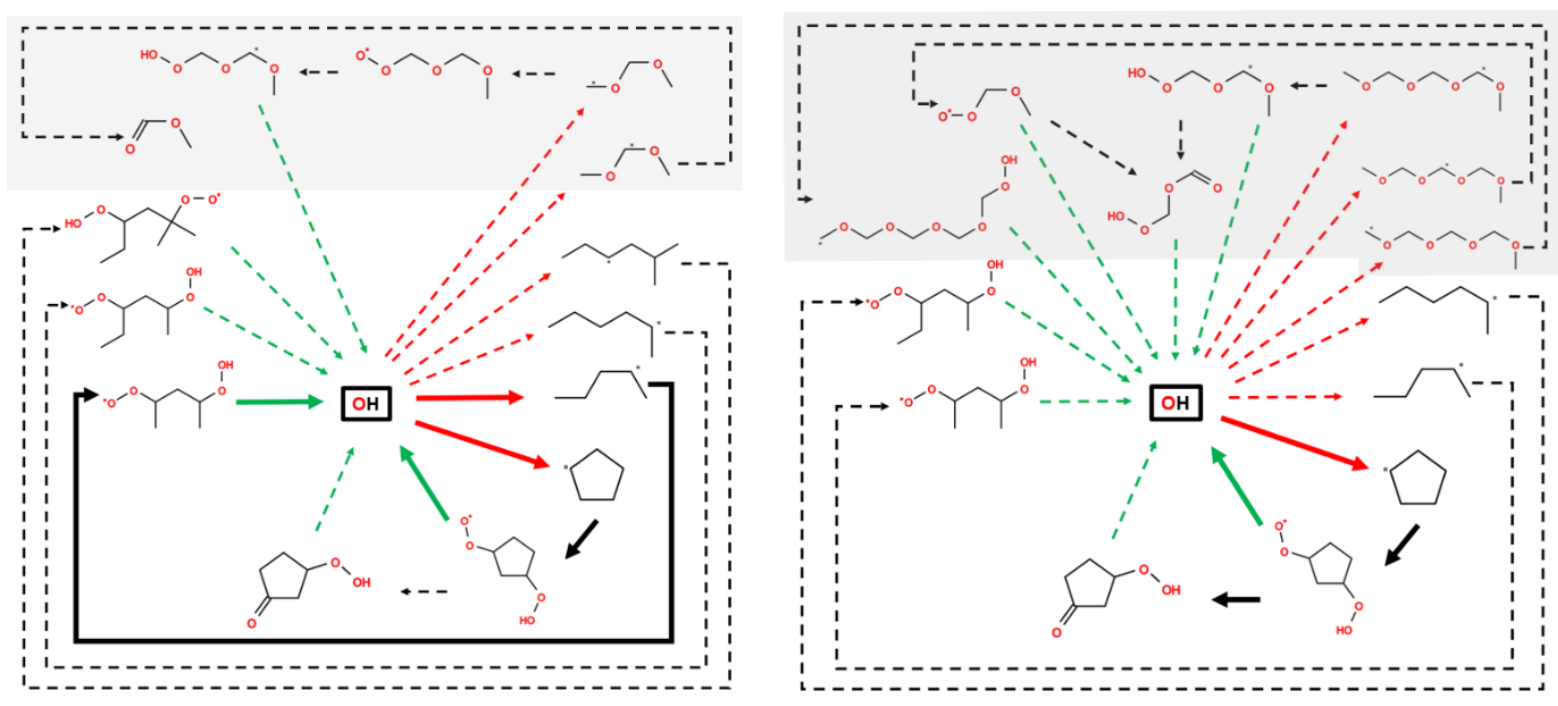

Figure 9 - Impact of OME chain length on main OH formation pathways in zone \#10 ( $\phi=$ 0.57, $756 \mathrm{~K})$ of IQT reactor at $t=10 \% \tau_{\text {id }}$ for light naphtha $+10 \%$ OME mixtures. Left : methylal. Right : $O M E_{3}$. Continuous and dashed lines correspond respectively to fluxes higher than $5 \mathrm{mmol} . \mathrm{m}^{-3} . \mathrm{s}^{-1}$ and fluxes ranging from 1 to $5 \mathrm{mmol} . \mathrm{m}^{-3} . \mathrm{s}^{-1}$. Red and green lines correspond respectively to $\mathrm{OH}$ consuming and $\mathrm{OH}$ producing pathways. The shaded area depicts the ether-related paths.

Previous studies put forward that the formaldehyde released by polyoxymethylene ethers could potentially inhibit ignition at initial temperatures lower than $900 \mathrm{~K}^{88}$. In fact, Yamada et al. ${ }^{89}$ mentioned a radical scavenging effect involving formaldehyde through reaction (E15)

$$
\mathrm{CH}_{2} \mathrm{O}+\mathrm{OH} \rightarrow \mathrm{HCO}+\mathrm{H}_{2} \mathrm{O}
$$


thereby removing $\mathrm{OH}$ radicals for base fuel oxidation. The present model confirms that this reaction corresponds in fact to the main consumption channel of formaldehyde under the present conditions at $10 \% \tau_{\mathrm{id}}$ (representing around $60 \%$ of total consumption rate). However, even if the addition of $10 \%$ dimethoxymethane (respectively $\mathrm{OME}_{3}$ ) to light naphtha results in an enhancement of the rate of (E8) by a factor of 22 (respectively a factor of 5) at $10 \% \tau_{\text {id }}$, the $\mathrm{OH}$ removal rate by $\mathrm{CH}_{2} \mathrm{O}\left(0.029 \mu \mathrm{mol} . \mathrm{m}^{-3} . \mathrm{s}^{-1}\right.$ in zone $\# 10$ at $\left.10 \% \tau_{\mathrm{id}}\right)$ lies still five orders of magnitude below the overall $\mathrm{OH}$ consumption rate (Figure 9). The contribution of (E15) to overall $\mathrm{OH}$ consumption increases to roughly $0.1 \%$ at $30 \% \tau_{\mathrm{id}}$, therefore remaining insignificant during the preignition phase. Hence, the inhibition of light naphtha ignition by dimethoxymethane does not result from supplementary $\mathrm{CH}_{2} \mathrm{O}$ production but is rather a consequence of the balance between $\mathrm{OH}$ consumption by methylal and $\mathrm{OH}$ production from hydroperoxy ether radicals formed during its oxidation (Figure 9).

The impact of local equivalence ratio on $\mathrm{OH}$ formation pathways is displayed on Figure 10. As can be seen, under very lean conditions neopentane supersedes n-hexane as a major contributor to $\mathrm{OH}$ consumption paths. Complementary calculations of neopentane / air and n-hexane / air constant volume autoignition at $21 \mathrm{bar}$ and $750 \mathrm{~K}$ indicate higher reactivities of neopentane at $\phi<0.1$. This confirms the trend observed and highlights the need for further investigation of fuel oxidation chemistry in ultra-lean conditions. DMM3C $(\mathrm{COCO}[\mathrm{CH}] \mathrm{OCOC})$ oxidation route runs through $\mathrm{C}_{3}$ instead of $\mathrm{C}_{2}$ ethers. However, in all IQT zones, $\mathrm{HO}_{2} \mathrm{CH}_{2} \mathrm{OCHO}$ remains a hub for $\mathrm{OH}$ production paths.
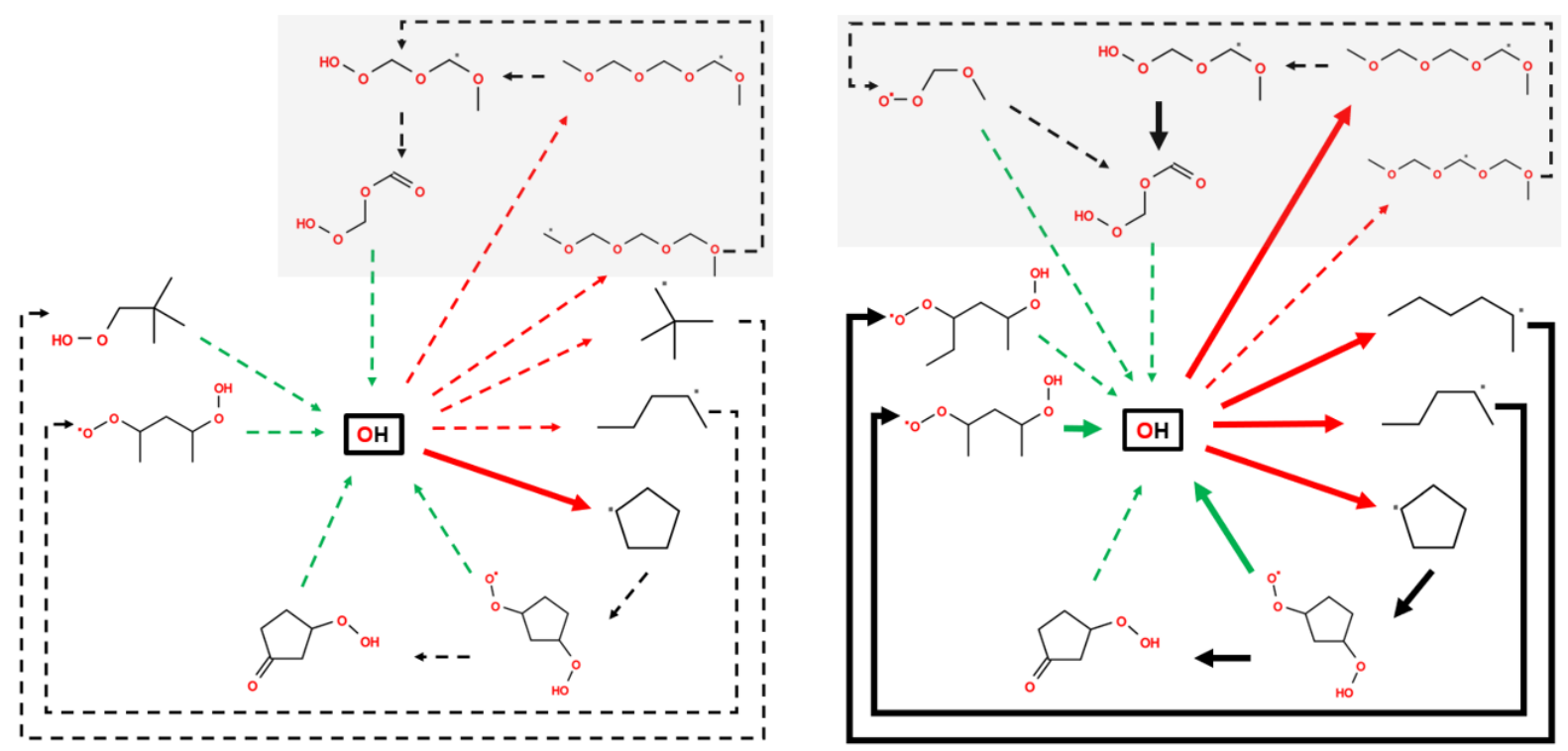

Figure 10 - Impact of local thermochemical state in the IQT reactor on main OH formation pathways at $10 \% \tau_{\text {id }}$ for light naphtha $+10 \%$ OME 3 . Left : zone \#1, $\phi=0.016,817 \mathrm{~K}$. Right : zone \#15, $\phi=1.10,718 \mathrm{~K}$. Continuous and dashed lines correspond respectively to fluxes

higher than 0.1 and fluxes ranging from 0.05 to $0.1 \mathrm{mmol} . \mathrm{m}^{-3} . \mathrm{s}^{-1}$. Red and green lines correspond respectively to $\mathrm{OH}$ consuming and $\mathrm{OH}$ producing pathways. The shaded area depicts the ether-related paths. 


\section{Conclusions}

The spontaneous ignition of mixtures of commercial distillates and a variety of ethers was studied both experimentally and computationally, allowing to unravel the impact of distillate composition, ether structure and reaction progress on key ignition pathways. The synergy between fuel and DNBE leads to the reversal of the expected order of promoting effects (DNBE $<$ DEE) from linear blending rules. The synergy is less pronounced in presence of p-xylene, partly due to vigourous $\mathrm{OH}$ radical scavenging. Ether and naphtha components interact mainly through the $\mathrm{C}_{0}-\mathrm{C}_{4}$ radical pool : direct cross-reactions have a negligible impact on ignition delay time under the present IQT conditions. Phenomenologically, two preignition phases may be distinguished, namely oxidation initiation by ether and subsequent chemical runaway involving simultaneous oxidations of fuel and ether. Regardless of distillate composition, ether contribution to $\mathrm{OH}$ production decreases with time, whereas oxidation paths related to aliphatic and cyclic alkanes become dominant for times higher than $1 \% \tau_{\text {id. }}$ In the case of polyoxymethylene methyl ethers, the extra production of formaldehyde during ignition phase does not significantly impact the overall reactivity. The respective effects of dimethoxymethane and $\mathrm{OME}_{\mathrm{x}}$ on ignition delay times may be attributed to the emergence of a new $\mathrm{OH}$ production path from hydroperoxy-methyl formate $\left(\mathrm{HO}_{2} \mathrm{CH}_{2} \mathrm{OCHO}\right)$, while methyl formate production from $\mathrm{OME}_{1}$ acts as an $\mathrm{OH}$ radical sink. Considering different $\mathrm{OME}_{\mathrm{x}}$ blends and associated surrogates would be useful in further unravelling these complex structure-dependent effects on reactivity. While locally lean zones of IQT reactor may favor neopentane oxidation at the expense of $n$-hexane, $\mathrm{HO}_{2} \mathrm{CH}_{2} \mathrm{OCHO}$ path for $\mathrm{OH}$ production remains active over a wide range of local equivalence ratios. Overall, the present detailed model qualitatively captures the nonlinear impact of various ethers on autoignition over the 15-30 DCN range, which makes it attractive for optimizing low cetane fuels formulation. The very stringent accuracy requirements for quantitative DCN predictions over an extended reactivity range (i.e. error on ignition delay time $<10 \%$ ) highlight the importance of more accurate ignition kinetics for a much wider spectrum of species than just conventional n-heptane / isoctane / toluene mixtures as well as advanced multicomponent multiphase turbulent reactive flows models.

\section{Acknowledgments}

The authors thank Mr. Sandoval for performing MUM-PCE calculations and Ms. Nadiya Nair for reviewing the manuscript. The work at King Abdullah University of Science and Technology (KAUST) was supported by the KAUST Clean Fuels Consortium (KCFC) and its member companies. 


\section{References}

(1) Sarathy, S.M.; Farooq, A.; Kalghatgi, G. T. Recent progress in gasoline surrogate fuels. Progress in Energy and Combustion Science 2018, 65, 67-108.

(2) Kalghatgi, G.; Levinsky, H.; Colket, M. Future transportation fuels. Progress in Energy and Combustion Science 2018, 69, 103-105.

(3) Liu, H.; Wang, Z.; Li, Y.; Zheng, Y.; He, T.; Wang, J. Recent progress in the application in compression ignition engines and the synthesis technologies of polyoxymethylene dimethyl ethers. Applied Energy 2019, 233-234, 599-611.

(4) Badra, J.; Viollet, Y.; Elwardany, A.; Im, H. G.; Chang, J. Physical and chemical effects of low octane gasoline fuels on compression ignition combustion. Applied Energy 2016, 183, 1197-1208.

(5) Davis, A. C.; Sarathy, S. M. Computational study of the combustion and atmospheric decomposition of 2-methylfuran. The journal of physical chemistry. A 2013, 117, 7670-7685.

(6) He, T.; Wang, Z.; You, X.; Liu, H.; Wang, Y.; Li, X.; He, X. A chemical kinetic mechanism for the low- and intermediate-temperature combustion of Polyoxymethylene Dimethyl Ether 3 (PODE3). Fuel 2018, 212, 223-235.

(7) Al Rashidi, M. J.; Davis, A. C.; Sarathy, S. M. Kinetics of the high-temperature combustion reactions of dibutylether using composite computational methods. Proceedings of the Combustion Institute 2015, 35, 385-392.

(8) Tripathi, R.; Lee, C.; Fernandes, R. X.; Olivier, H.; Curran, H. J.; Mani Sarathy, S.; Pitsch, H. Ignition characteristics of 2-methyltetrahydrofuran: An experimental and kinetic study. Proceedings of the Combustion Institute 2017, 36, 587-595.

(9) Vermeire, F. H.; Carstensen, H.-H.; Herbinet, O.; Battin-Leclerc, F.; Marin, G. B.; van Geem, K. M. Experimental and modeling study of the pyrolysis and combustion of dimethoxymethane. Combustion and Flame 2018, 190, 270-283.

(10) Serinyel, Z.; Lailliau, M.; Thion, S.; Dayma, G.; Dagaut, P. An experimental chemical kinetic study of the oxidation of diethyl ether in a jet-stirred reactor and comprehensive modeling. Combustion and Flame 2018, 193, 453-462.

(11) Kröger, L. C.; Döntgen, M.; Firaha, D.; Kopp, W. A.; Leonhard, K. Ab initio kinetics predictions for H-atom abstraction from diethoxymethane by hydrogen, methyl, and ethyl radicals and the subsequent unimolecular reactions. Proceedings of the Combustion Institute 2018, DOI: 10.1016/j.proci.2018.06.056.

(12) Peukert, S.; Sela, P.; Nativel, D.; Herzler, J.; Fikri, M.; Schulz, C. Direct Measurement of HighTemperature Rate Constants of the Thermal Decomposition of Dimethoxymethane, a Shock Tube and Modeling Study. The journal of physical chemistry. A 2018, 122, 7559-7571.

(13) Huang, H.; Li, Z.; Teng, W.; Huang, R.; Liu, Q.; Wang, Y. Effects of EGR rates on combustion and emission characteristics in a diesel engine with n-butanol/PODE3-4/diesel blends. Applied Thermal Engineering 2019, 146, 212-222.

(14) Khalife, E.; Tabatabaei, M.; Demirbas, A.; Aghbashlo, M. Impacts of additives on performance and emission characteristics of diesel engines during steady state operation. Progress in Energy and Combustion Science 2017, 59, 32-78.

(15) Barik, D.; Murugan, S. Effects of diethyl ether (DEE) injection on combustion performance and emission characteristics of Karanja methyl ester (KME)-biogas fueled dual fuel diesel engine. Fuel 2016, 164, 286-296.

(16) Tripathi, R.; Burke, U.; Ramalingam, A. K.; Lee, C.; Davis, A. C.; Cai, L.; Selim, H.; Fernandes, R. X.; Heufer, K. A.; Sarathy, S. M. et al. Oxidation of 2-methylfuran and 2-methylfuran/n-heptane blends: An experimental and modeling study. Combustion and Flame 2018, 196, 54-70.

(17) Singh, E.; Shankar, V. S. B.; Tripathi, R.; Pitsch, H.; Sarathy, S. M. 2-Methylfuran: A bio-derived octane booster for spark-ignition engines. Fuel 2018, 225, 349-357. 
(18) Jiang, X.; Tian, Z.; Zhang, Y.; Huang, Z. Shock tube measurement and simulation of DME/nbutane/air mixtures: Effect of blending in the NTC region. Fuel 2017, 203, 316-329.

(19) Wu, H.; Shi, Z.; Lee, C.-f.; Zhang, H.; Xu, Y. Experimental and kinetic study on ignition of DME/ $\mathrm{n}$-butane mixtures under high pressures on a rapid compression machine. Fuel 2018, 225, 35-46.

(20) Howard, M. S.; Issayev, G.; Naser, N.; Sarathy, S. M.; Farooq, A.; Dooley, S. Ethanolic gasoline, a lignocellulosic advanced biofuel. Sustainable Energy Fuels 2019, 3, 409-421.

(21) Sivasankaralingam, V.; Raman, V.; Mubarak Ali, M. J.; Alfazazi, A.; Lu, T.; Im, H.; Sarathy, S. M.; Dibble, R. Experimental and Numerical Investigation of Ethanol/Diethyl Ether Mixtures in a CI Engine. In ; SAE Technical Paper. 2016.

(22) Górski, K.; Przedlacki, M. Evaluation of the Influence of Diethyl Ether (DEE) Addition on Selected Physicochemical Properties of Diesel Oil and Ignition Delay Period. Energy Fuels 2014, 28, 2608-2616.

(23) Ren, Y.; Huang, Z.; Miao, H.; Di, Y.; Jiang, D.; Zeng, K.; Liu, B.; Wang, X. Combustion and emissions of a DI diesel engine fuelled with diesel-oxygenate blends. Fuel 2008, 87, 2691-2697.

(24) Keith D. Vertin, James M. Ohi, David W. Naegeli, Kenneth H. Childress, Gary P. Hagen, Chris I. McCarthy, Adelbert S. Cheng, Robert W. Dibble, Methylal and Methylal-Diesel Blended Fuels for Use in Compression-Ignition Engines. SAE Technical Paper. 1999.

(25) Sezer, İ. Thermodynamic performance and emission investigation of a diesel engine running on dimethyl ether and diethyl ether. International Journal of Thermal Sciences 2011, 50, 1594-1603.

(26) Liu, H.; Wang, Z.; Li, B.; Wang, J.; He, X. Exploiting new combustion regime using multiple premixed compression ignition (MPCI) fueled with gasoline/diesel/PODE (GDP). Fuel 2016, 186, 639647.

(27) Jiang, X.; Zhang, Y.; Man, X.; Pan, L.; Huang, Z. Shock Tube Measurements and Kinetic Study on Ignition Delay Times of Lean DME/ n -Butane Blends at Elevated Pressures. Energy Fuels 2013, 27, 6238-6246.

(28) Jiang, X.; Zhang, Y.; Man, X.; Pan, L.; Huang, Z. Experimental and Modeling Study on Ignition Delay Times of Dimethyl Ether/ n -Butane Blends at a Pressure of 2.0 MPa. Energy Fuels 2014, 28, 2189-2198.

(29) Jiang, X.; Deng, F.; Yang, F.; Huang, Z. Ignition Delay Characteristics and Kinetic Investigation of Dimethyl Ether/ $\mathrm{n}$-Pentane Binary Mixtures: Interpreting the Effect of the Equivalence Ratio and Dimethyl Ether Blending. Energy Fuels 2018, 32, 3814-3823.

(30) Jin, H.; Pieper, J.; Hemken, C.; Bräuer, E.; Ruwe, L.; Kohse-Höinghaus, K. Chemical interaction of dual-fuel mixtures in low-temperature oxidation, comparing $\mathrm{n}$-pentane/dimethyl ether and $\mathrm{n}$ pentane/ethanol. Combustion and Flame 2018, 193, 36-53.

(31) Dames, E. E.; Rosen, A. S.; Weber, B. W.; Gao, C. W.; Sung, C.-J.; Green, W. H. A detailed combined experimental and theoretical study on dimethyl ether/propane blended oxidation. Combustion and Flame 2016, 168, 310-330.

(32) Hess, H. S.; Szybist, J.; Boehman, A. L.; Tijm, P.J.A.; Waller, F. J. Impact of oxygenated fuel on diesel engine performance and emissions. Proceedings of the National Heat Transfer Conference 2001, $1,931-941$.

(33) Clothier, P.Q.E.; Moise, A.; Pritchard, H. O. Effect of free-radical release on diesel ignition delay under simulated cold-starting conditions. Combustion and Flame 1990, 81, 242-250.

(34) Zhang, Y.; Somers, K. P.; Mehl, M.; Pitz, W. J.; Cracknell, R. F.; Curran, H. J. Probing the antagonistic effect of toluene as a component in surrogate fuel models at low temperatures and high pressures. A case study of toluene/dimethyl ether mixtures. Proceedings of the Combustion Institute 2017, 36, 413-421.

(35) Fikri, M.; Sakai, Y.; Herzler, J.; Schulz, C. Experimental and numerical study of the ignition delay times of primary reference fuels containing diethyl ether. 26th ICDERS, Boston, MA 2017.

(36) Liu, H.; Ma, X.; Li, B.; Chen, L.; Wang, Z.; Wang, J. Combustion and emission characteristics of a direct injection diesel engine fueled with biodiesel and PODE/biodiesel fuel blends. Fuel 2017, 209, 62-68. 
(37) Huang, H.; Liu, Q.; Teng, W.; Pan, M.; Liu, C.; Wang, Q. Improvement of combustion performance and emissions in diesel engines by fueling n-butanol/diesel/PODE3-4 mixtures. Applied Energy 2018, 227, 38-48.

(38) Liu, H.; Wang, Z.; Wang, J.; He, X.; Zheng, Y.; Tang, Q.; Wang, J. Performance, combustion and emission characteristics of a diesel engine fueled with polyoxymethylene dimethyl ethers (PODE3-4)/ diesel blends. Energy 2015, 88, 793-800.

(39) Chen, H.; He, J.; Hua, H. Investigation on Combustion and Emission Performance of a Common Rail Diesel Engine Fueled with Diesel/Biodiesel/Polyoxymethylene Dimethyl Ethers Blends. Energy Fuels 2017, 31, 11710-11722.

(40) Hu, E.; Gao, Z.; Liu, Y.; Yin, G.; Huang, Z. Experimental and modeling study on ignition delay times of dimethoxy methane/ $\mathrm{n}$-heptane blends. Fuel 2017, 189, 350-357.

(41) Wang, Z.; Liu, H.; Ma, X.; Wang, J.; Shuai, S.; Reitz, R. D. Homogeneous charge compression ignition (HCCI) combustion of polyoxymethylene dimethyl ethers (PODE). Fuel 2016, 183, 206-213.

(42) Bogin, G. E.; Luecke, J.; Ratcliff, M. A.; Osecky, E.; Zigler, B. T. Effects of iso-octane/ethanol blend ratios on the observance of negative temperature coefficient behavior within the Ignition Quality Tester. Fuel 2016, 186, 82-90.

(43) Naik, C. V.; Puduppakkam, K.; Wang, C.; Kottalam, J.; Liang, L.; Hodgson, D.; Meeks, E. Applying Detailed Kinetics to Realistic Engine Simulation: The Surrogate Blend Optimizer and Mechanism Reduction Strategies. SAE Int. J. Engines 2010, 3, 241-259.

(44) Ahmed, A.; Goteng, G.; Shankar, V. S.B.; Al-Qurashi, K.; Roberts, W. L.; Sarathy, S. M. A computational methodology for formulating gasoline surrogate fuels with accurate physical and chemical kinetic properties. Fuel 2015, 143, 290-300.

(45) Kim, D.; Violi, A. Hydrocarbons for the next generation of jet fuel surrogates. Fuel 2018, 228, 438-444.

(46) Hanwell, M. D.; Curtis, D. E.; Lonie, D. C.; Vandermeersch, T.; Zurek, E.; Hutchison, G. R. Avogadro: An advanced semantic chemical editor, visualization, and analysis platform. Journal of cheminformatics 2012, 4, 17.

(47) Halgren, T. A. Merck molecular force field. I. Basis, form, scope, parameterization, and performance of MMFF94. J. Comput. Chem. 1996, 17, 490-519.

(48) Zheng, Y.; Tang, Q.; Wang, T.; Liao, Y.; Wang, J. Synthesis of a Green Fuel Additive Over Cation Resins. Chem. Eng. Technol. 2013, 36, 1951-1956.

(49) Arteconi, A.; Mazzarini, A.; Di Nicola, G. Emissions from Ethers and Organic Carbonate Fuel Additives: A Review. Water Air Soil Pollut 2011, 221, 405-423.

(50) Naser, N. Autoignition behavior of practical fuels, PhD Thesis, King Abdullah University of Science and Technology, 2018.

(51) Yang, S. Y.; Naser, N.; Chung, S. H.; Cha, J. Effect of Temperature, Pressure and Equivalence Ratio on Ignition Delay in Ignition Quality Tester (IQT): Diesel, n -Heptane, and iso -Octane Fuels under Low Temperature Conditions. SAE Int. J. Fuels Lubr. 2015, 8, 537-548.

(52) Naser, N.; Yang, S. Y.; Kalghatgi, G.; Chung, S. H. Relating the octane numbers of fuels to ignition delay times measured in an ignition quality tester (IQT). Fuel 2017, 187, 117-127.

(53) Bogin Jr, G. E.; Dean, A. M.; DeFilippo, A.; Chen, J. Y.; Chin, G.; Luecke, J.; Ratcliff, M. A.; Zigler, B. T. Modeling the Fuel Spray and Combustion Process of the Ignition Quality Tester with KIVA3V, NREL Report, 2010.

(54) Barraza-Botet, C. L.; Luecke, J.; Zigler, B. T.; Wooldridge, M. S. The impact of physicochemical property interactions of iso-octane/ethanol blends on ignition timescales. Fuel 2018, 224, 401-411.

(55) Ji, C.; Dec, J. E.; Dernotte, J.; Cannella, W. Effect of Ignition Improvers on the Combustion Performance of Regular-Grade E10 Gasoline in an HCCI Engine. SAE Int. J. Engines 2014, 7, 790-806.

(56) Amann M., Ryan T.W., Kono, N., HCCI Fuels Evaluations-Gasoline Boiling Range Fuels. SAE Technical Paper. 2005. 
(57) Perez, P. L.; Boehman, A. L. Experimental Investigation of the Autoignition Behavior of Surrogate Gasoline Fuels in a Constant-Volume Combustion Bomb Apparatus and Its Relevance to HCCI Combustion. Energy Fuels 2012, 26, 6106-6117.

(58) Dahmen, M.; Marquardt, W. A Novel Group Contribution Method for the Prediction of the Derived Cetane Number of Oxygenated Hydrocarbons. Energy Fuels 2015, 29, 5781-5801.

(59) Naser, N.; Sarathy, S. M.; Chung, S. H. Ignition delay time sensitivity in ignition quality tester (IQT) and its relation to octane sensitivity. Fuel 2018, 233, 412-419.

(60) Knothe, G.; Matheaus, A. C.; Ryan, T. W. Cetane numbers of branched and straight-chain fatty esters determined in an ignition quality tester. Fuel 2003, 82, 971-975.

(61) Sarathy, S. M.; Kukkadapu, G.; Mehl, M.; Javed, T.; Ahmed, A.; Naser, N.; Tekawade, A.; Kosiba, G.; AlAbbad, M.; Singh, E. et al. Compositional effects on the ignition of FACE gasolines. Combustion and Flame 2016, 169, 171-193.

(62) Daviault, S. Characterization of the fuel injection process within the ignition quality tester (IQT (TM)), Carleton University, 2011.

(63) Tran, L.-S.; Herbinet, O.; Li, Y.; Wullenkord, J.; Zeng, M.; Bräuer, E.; Qi, F.; Kohse-Höinghaus, K.; Battin-Leclerc, F. Low-temperature gas-phase oxidation of diethyl ether: Fuel reactivity and fuelspecific products. Proceedings of the Combustion Institute 2018, DOI: 10.1016/j.proci.2018.05.135.

(64) Tran, L.-S.; Pieper, J.; Carstensen, H.-H.; Zhao, H.; Graf, I.; Ju, Y.; Qi, F.; Kohse-Höinghaus, K. Experimental and kinetic modeling study of diethyl ether flames. Proceedings of the Combustion Institute 2017, 36, 1165-1173.

(65) Thion, S.; Togbé, C.; Serinyel, Z.; Dayma, G.; Dagaut, P. A chemical kinetic study of the oxidation of dibutyl-ether in a jet-stirred reactor. Combustion and Flame 2017, 185, 4-15.

(66) Cai, L.; Sudholt, A.; Lee, D. J.; Egolfopoulos, F. N.; Pitsch, H.; Westbrook, C. K.; Sarathy, S. M. Chemical kinetic study of a novel lignocellulosic biofuel: Di-n-butyl ether oxidation in a laminar flow reactor and flames. Combustion and Flame 2014, 161, 798-809.

(67) Sun, W.; Wang, G.; Li, S.; Zhang, R.; Yang, B.; Yang, J.; Li, Y.; Westbrook, C. K.; Law, C. K. Speciation and the laminar burning velocities of poly(oxymethylene) dimethyl ether 3 (POMDME3) flames: An experimental and modeling study. Proceedings of the Combustion Institute 2017, 36, 12691278.

(68) Sun, W.; Tao, T.; Lailliau, M.; Hansen, N.; Yang, B.; Dagaut, P. Exploration of the oxidation chemistry of dimethoxymethane: Jet-stirred reactor experiments and kinetic modeling. Combustion and Flame 2018, 193, 491-501.

(69) Reaction Design. Chemkin-pro release 15131. Reaction Design, San Diego, CA 2013.

(70) Aceves, S. M.; Flowers, D. L.; Martinez-Frias, J.; Smith, J. R.; Westbrook, C. K.; Pitz, W. J.; Dibble, R.; Wright, J. F.; Akinyemi, W. C.; Hessel, R. P. A Sequential Fluid-Mechanic ChemicalKinetic Model of Propane HCCI Combustion. SAE Technical Paper. 2001.

(71) Jaasim M., Elhagrasy A., Sarathy M., Chung S.H., Im H.G., Auto-Ignition and Spray Characteristics of n-Heptane and iso-Octane Fuels in Ignition Quality Tester; SAE Technical Paper. 2018.

(72) Guan, L.; Tang, C.; Yang, K.; Mo, J.; Huang, Z. Effect of di-n-butyl ether blending with soybeanbiodiesel on spray and atomization characteristics in a common-rail fuel injection system. Fuel 2015, $140,116-125$.

(73) Seo, J.; Kim, H. Y.; Park, S.; James, S. C.; Yoon, S. S. Experimental and Numerical Simulations of Spray Impingement and Combustion Characteristics in Gasoline Direct Injection Engines under Variable Driving Conditions. Flow Turbulence Combust 2016, 96, 391-415.

(74) Bi, S.; Zhao, G.; Wu, J. Surface Tension of Diethyl Ether, Diisopropyl Ether, and Dibutyl Ether. J. Chem. Eng. Data 2010, 55, 1523-1526.

(75) Osecky, E. M.; Bogin, G. E.; Villano, S. M.; Ratcliff, M. A.; Luecke, J.; Zigler, B. T.; Dean, A. M. Investigation of Iso-octane Ignition and Validation of a Multizone Modeling Method in an Ignition Quality Tester. Energy Fuels 2016, 30, 9761-9771. 
(76) Glarborg, P.; Kee, R. J.; Grcar, J. F.; Miller, J. A. PSR: A FORTRAN program for modeling wellstirred reactors. Sandia Report SAND86-8209 1986.

(77) Ra, Y.; Reitz, R. D. A vaporization model for discrete multi-component fuel sprays. International Journal of Multiphase Flow 2009, 35, 101-117.

(78) Weisser, G. A. Modelling of combustion and nitric oxide formation for medium-speed DI diesel engines: A comparative evaluation of zero-and three-dimensional approaches, ETH Zurich, 2001.

(79) Twu, C.; Coon, J. A generalized interaction method for the prediction of octane numbers for gasoline blends. Simulation Science Inc 1998, 1-18.

(80) Lorentz, H. A. Ueber die Anwendung des Satzes vom Virial in der kinetischen Theorie der Gase. Ann. Phys. 1881, 248, 127-136.

(81) Wang, H.; Sheen, D. A. Combustion kinetic model uncertainty quantification, propagation and minimization. Progress in Energy and Combustion Science 2015, 47, 1-31.

(82) Vom Lehn, F.; Cai, L.; Pitsch, H. Sensitivity analysis, uncertainty quantification, and optimization for thermochemical properties in chemical kinetic combustion models. Proceedings of the Combustion Institute 2019, 37, 771-779.

(83) Gao, C. W.; Allen, J. W.; Green, W. H.; West, R. H. Reaction Mechanism Generator: Automatic construction of chemical kinetic mechanisms. Computer Physics Communications 2016, 203, 212-225.

(84) O'Boyle, N. M.; Banck, M.; James, C. A.; Morley, C.; Vandermeersch, T.; Hutchison, G. R. Open Babel: An open chemical toolbox. Journal of cheminformatics 2011, 3, 33.

(85) Moshammer, K.; Jasper, A. W.; Popolan-Vaida, D. M.; Lucassen, A.; Diévart, P.; Selim, H.; Eskola, A. J.; Taatjes, C. A.; Leone, S. R.; Sarathy, S. M. et al. Detection and Identification of the KetoHydroperoxide $\left(\mathrm{HOOCH}_{2} \mathrm{OCHO}\right)$ and Other Intermediates during Low-Temperature Oxidation of Dimethyl Ether. The journal of physical chemistry. A 2015, 119, 7361-7374.

(86) Gao, J.; Nakamura, Y. Low-temperature ignition of dimethyl ether: Transition from cool flame to hot flame promoted by decomposition of $\mathrm{HPMF}\left(\mathrm{HO}_{2} \mathrm{CH}_{2} \mathrm{OCHO}\right)$. Combustion and Flame 2016, 165, $68-82$.

(87) Akih-Kumgeh, B.; Bergthorson, J. M. Shock Tube Study of Methyl Formate Ignition. Energy Fuels 2010, 24, 396-403.

(88) Kuwahara, K.; Ando, H.; Furutani, M.; Ohta, Y. Impact of Formaldehyde Addition on AutoIgnition in Internal-Combustion Engines. JSME Int. J., Ser. B 2005, 48, 708-716.

(89) Yamada, H.; Suzaki, K.; Sakanashi, H.; Choi, N.; Tezaki, A. Kinetic measurements in homogeneous charge compression of dimethyl ether: Role of intermediate formaldehyde controlling chain branching in the low-temperature oxidation mechanism. Combustion and Flame 2005, 140, 24 33. 